УДК 616.24-002.828-006

DOI: $10.26435 /$ UC.V0I4(33).365

\author{
Н.В. Пискунова, И.А. Колесникова, К.В. Поляков, О.О. Юрченко
}

ГОО ВПО «Донецкий национальный медицинский университет имени М. Горького», Донецк

\title{
АСПЕРГИЛЛЕЗ ЛЕГКИХ - АСПЕРГИЛЛЕМА (НАБЛЮДЕНИЕ ИЗ ПРАКТИКИ)
}

Аспергиллёз лёгких - заболевание грибковой этиологии, которое поражает все отделы дыхательной системы, протекает в острой или хронической форме, характеризуется разнообразием клинических симптомов. Частота аспергиллеза в настоящее время значительно возросла, занимает второе место после кандидамикоза, что обусловлено увеличением числа больных с иммунодефицитом. Так, по данным вскрытий, частота инвазивного аспергиллеза увеличилась от 0,59\% до 3,77\% [1, 2].

Основной путь инфицирования респираторный, входные ворота трахео-бронхиольное дерево, где происходит созревание спор и прорастание мицелия в окружающие ткани, они оказывают токсическое, протеолитическое и ангиотропное действие. Здоровый человек быстро избавляется от грибов благодаря легочным макрофагам и нейтрофилам. Однако на фоне иммуносупрессии возбудитель продолжает размножаться, проникает в ткани и кровеносные сосуды, вызывая некроз и гематогенную генерализацию. Аллергизирующее действие грибов приводит к анафилаксии, что проявляется бронхоспазмом, повышением иммуноглобулина Е и эозинофилией. Часто присоединяется бактериальная флора с развитием гнойного воспаления и абсцедирования [3].

К клиническим формам бронхо-легочного аспергиллеза относятся аспергиллезный бронхит, трахеобронхит, бронхопневмония, диффузный аспергиллез легких, аспергиллема легких, аллергический аспергиллез легких, аспергиллез плевры, атипические формы аспергиллеза легких [1].

Локализованная форма бронхо-легочного аспергиллеза называется аспергиллема легкого. Представляет собой округлую или овальную полость, сообщающуюся с бронхом, внутри содержатся грибковые массы - биссус. Выделяют две формы аспергиллемы - первичная и вторичная: первичные аспергиллемы возникают в здоровых тканях легкого, без наличия предсуществующей полости, бывают редко (1-18\%). Вторич- ные аспергиллемы (до 72\% всех случаев) развиваются в ранее предсуществующей полости: туберкулезная каверна, абсцесс, гангрена, после распада раковой опухоли и прочие, представляя собой грибной шар в полости $[2,4]$. Аспергиллема чаще одиночная, локализуется в верхней доле правого легкого, реже в левом легком. Описаны случаи и множественных аспергиллом в обоих легких, в связи с изменением легочной архитектоники и образованием множества полостей: бронхоэктатическая болезнь, поликистоз легких $[1,5]$.

Для диагностики аспергиллемы используют рентгенографию, компьютерную и магнитнорезонансную томографию, бактериологический и серологический методы исследования. В прижизненной диагностике аспергиллеза проводят исследование мокроты, аспирата, применяются серологические реакций со специфическим антигеном. Одним из важных критериев диагностики является определение антител к антигенам гриба, что подтверждено в 71\%-93\% случаев больных аспергиллемой $[1,5]$. Для выявления аспергилл используются окрашивание препаратов по методу Шабадаша, Гомори-Грокотта, серебрение по Футу.

Приводим клинико-морфологический случай аспергиллемы легкого.

Больной Д. 80 лет, поступил в ургентном порядке в пульмонологическое отделение с жалобами на кашель с трудно отделяемой мокротой черного цвета, одышку при физической нагрузке, головную боль, отсутствие аппетита, исхудание на 10 килограмм за полторы недели, общую слабость. Считает себя больным около двух недель, до этого находился на амбулаторном лечении по месту жительства с диагнозом: Левосторонняя верхнедолевая пневмония? Туберкулез? При проведении компьютерной томографии в

(c) Н.В. Пискунова, И.А. Колесникова,

К.В. Поляков, О.О. Юрченко, 2019

(c) Университетская Клиника, 2019 
верхней доле левого легкого обнаружено периферическое многокамерное образование с толстыми стенками. Больной был консультирован онкологом, выставлен диагноз: «абсцедирующая верхнедолевая пневмония слева», фтизиатром: «эндобронхит». При бронхо-альвеолярном лаваже микроорганизмы не обнаружены. При рентгенографии легких в верхней доле слева определяется очаг деструкции ткани с наличием полости и секвестром внутри. Заключение: необходимо дифференцировать между распадающейся периферической опухолью легкого, абсцессом, туберкулезной каверной.

Состояние больного прогрессивно ухудшалось, усилился кашель с отхождением большого количества гнойной мокроты, нарастала одышка, в связи с чем больной переведен на искусственную вентиляцию легких. Через сутки он умер от нарастающей легочной недостаточности и интоксикации.

Клинический диагноз:

- основной: Внегоспитальная пневмония верхней и нижней долей левого легкого с абсцедированием. Опухоль? Туберкулез?

- осложнения: Левосторонний экссудативный плеврит, экссудативный перикардит. Отек легких и головного мозга. Легочная недостаточность III степени.

- сопутствующий: Ишемическая болезнь сердца: очаговый постинфарктный кардиосклероз неизвестной давности и диффузный атеросклеротический кардиосклероз при гипертонической болезни. Хронический бронхит в стадии обострения.

При вскрытии трупа старого мужчины, пониженного питания, кожные покровы и слизистые оболочки синюшные, выраженный акроцианоз. В грудной полости следы прозрачной желтоватой жидкости. В области верхушки левого легкого между плевральными листками плотные пленчатые спайки, легкое выделяется с отрывом ткани, на остальном протяжении листки плевры гладкие блестящие, синюшные. В полости перикарда следы прозрачной, соломенного цвета жидкости, листки перикарда серовато-синюшные, влажные, гладкие, блестящие. В сердце - гипертрофия левого желудочка 1,9 см, постинфарктный рубец 3,5×2,0 см в нижней стенке левого желудочка, мелкоочаговый кардиосклероз, стенозирующий атеросклероз венечных артерий. В просвете гортани, трахеи и бронхов мутное, серовато-зеленоватое вязкое отделяемое. Слизистая оболочка дыхательных путей тусклая, полнокровная, набухшая. В области верхушки левого легкого определяется округлая полость диаметром 6,0 см, с четкими кон- турами, слегка западающей стенкой, заполненная коричневато-зеленоватой, темной, мутной, вязкой жидкостью с участками губчатого вида темно-серого и белесоватого цвета. В верхней и нижней долях левого легкого и в нижней доле правого легкого множественные участки уплотнения красновато-сероватого цвета от 1,5 до 3см, несколько выбухающие над поверхностью разреза. Бронхи выступают над поверхностью разреза в виде «гусиных перьев». При гистологическом исследовании стенка полости представлена тканью легкого с обширными участками некроза, гнойным воспалением, кровоизлияниями и разрастанием грануляционной ткани, а также частичками друз грибов аспергилла. Содержимое полости - некротические массы и обильное количество друз грибов аспергилла (подтверждено при окраске микропрепарата по Шабодашу). В бронхах - хронический бронхит в стадии обострения, в ткани легкого интерстициальная и очаговая гнойная пневмония, очаги эмфиземы, ателектаза и дистелектаза, кровоизлияния.

На основании данных вскрытия и гистологического исследования выставлен патологоанатомический диагноз:

- основной: Аспергиллез легких с абсцедированием и формированием аспергиллемы верхней доли левого легкого.

- осложнения: Двухсторонняя очаговая гнойная пневмония. Общее венозное полнокровие. Дистрофические изменения паренхиматозных органов. Отек легких.

- сопутствующий: Хронический бронхит в стадии обострения, эмфизема легких. Хроническая ишемическая болезнь сердца: постинфарктный и диффузный кардиосклероз при стенозирующем атеросклерозе венечных артерий и гипертонической болезни (толщина стенки левого желудочка 1,9 см).

Непосредственной причиной смерти больного явилась дыхательная недостаточность.

Основное заболевание развилось у больного на фоне тяжелой бронхо-легочной патологии.

Таким образом, описанная форма бронхолегочного аспергиллеза (аспергиллема) представляет значительные трудности в диагностике, так как не имеет специфических клинических проявлений, а рентгенологические изменения необходимо дифференцировать со многими заболеваниями. Своевременно поставленный диагноз и адекватная антимикотическая терапия, а в ряде случаев и хирургическое удаление аспергиллемы позволяет спасти жизнь больного. Знание этой патологии необходимо врачам многих специальностей. 


\section{Н.В. Пискунова, И.А. Колесникова, К.В. Поляков, О.О. Юрченко}

ГОО ВПО «Донецкий национальный медицинский университет имени М. Горького», Донецк

\section{АСПЕРГИЛЛЕЗ ЛЕГКИХ - АСПЕРГИЛЛЕМА (НАБЛЮДЕНИЕ ИЗ ПРАКТИКИ)}

В статье описан секционный случай аспергиллемы легкого, не диагностированной в клинике, проведено клинико-морфологическое сопоставление, от- мечена трудность в диагностике данной патологии.

Ключевые слова: аспергиллез, аспергиллема легких, наблюдение из практики.

\section{N.V. Piskunova, I.A. Kolesnikova, K.V. Polyakov, O.O. Yurchenko}

SEI HPE «M. Gorky Donetsk National Medical University», Donetsk

\section{LUNG ASPERGILLOSIS - ASPERGILLOMA (CASE FROM PRACTICE)}

Description of autopsy case of lung aspergilloma, which was not diagnosed in clinic, is presented in the article. Clinical-morphological comparison was performed, difficulty in diagnosing this pathology was marked.

Key words: aspergillosis, lung aspergilloma, case from practice.

\section{ЛИТЕРАТУРА}

1. Герман А.К., Растворов А.А., Шарапова И.М., Зубов В.Г., Скороходова Н.О. Аспергиллема (мицетома) - своеобразная форма легочного аспергиллеза. Дерматовенерология. Косметология. Сексопатология. 2007; 1-4 (10): 233-239.

2. Кораблина И.М., Цинзерлинг В.А., Аравийский Р.А. Аспергиллез по данным аутопсий в ленинградской областной клинической больнице с 2001 по 2010 гг. Проблемы медицинской микологии. 2011; 13 (2): 45-49.

3. Назарова М.А, Сулейменова 3.И., Сейдулаева Л.Б., Дуйсенова А.К., Курманова К.Б. Аспергиллёз. Вестник АГИУВ. 2012; 4: 43-46.

4. Лискина И.В., Кузовкова С.Д. Аспергиллема легкого. Международный медицинский журнал. 2011; 4: 41-47.

5. Митрофанов В.С., Свирщевская Е.В. Аспергиллез легких. СПб.: Фолиант; 2005. 144.

\section{REFERENCES}

1. German A.K., Rastvorov A.A., Sharapova I.M., Zubov V.G., Skorokhodova N.O. Aspergillema (mitsetoma) - svoeobraznaya forma legochnogo aspergilleza [Aspergilloma (mycetoma) - is peculiar form of lung aspergillosis]. Dermatovenerologiya. Kosmetologiya. Seksopatologiya. 2007; 1-4 (10): 233-239 (in Russian).

2. Korablina I.M., Tsinzerling V.A., Araviiskii R.A. Aspergillez po dannym autopsii v leningradskoi oblastnoi klinicheskoi bol'nitse s 2001 po 2010 gg [Aspergillosis according to autopsy data performed in Leningrad regional clinical hospital from 2001 till 2010]. Problemy meditsinskoi mikologii. 2011; 13 (2): 45-49 (in Russian).

3. Nazarova M.A, Suleimenova Z.I., Seidulaeva L.B., Duisenova A.K., Kurmanova K.B. Aspergillez [Aspergillosis]. Vestnik AGIUV. 2012; 4: 43-46 (in Russian).

4. Liskina I.V., Kuzovkova S.D. Aspergillema legkogo [Lung aspergilloma]. Mezhdunarodnyi meditsinskii zhurnal. 2011; 4: 41-47 (in Russian).

5. Mitrofanov V.S., Svirshchevskaya E.V. Aspergillez legkikh [Lung aspergillosis]. SPb.: Foliant; 2005. 144.. 